\title{
CARCINOMA IN THE UPPER THIRD OF THE OESOPHAGUS
}

\author{
By LIONEL COLLEDGE, F.R.C.S.(Eng.) \\ (Cons. Surg., Ear and Throat Dept., St. George's Hosp.)
}

The incidence of carcinoma in the oesophagus is considered to be about five per cent of the total incidence of cancer, rather more than in the larynx which is now a little over two per cent. In the oesophagus itself the upper third is the least common site. Thus Guisez found Iro cases in the upper third, I62 in the middle, and I34 in the lower third. According to Sauerbruch (quoted by Gluck) in I89 autppsies on cases of oesophageal carcinoma it occurred 26 times in the cervical portion. There has, however, been much variety of opinion on this point. Each third of the oesophagus has been held at some time to be the commonest site. Rolleston, quoting Butlin besides his own observations, arrived at no definite conclusion on this point, though some reliable observers found the upper third of the oesophagus to be by far the most common site. This discrepancy may be due in part to the inclusion of the post cricoid region of the pharynx in the oesophagus. At this level carcinoma is common, especially in women.

If the upper limit of the oesophagus is taken precisely as the lower border of the cricoid cartilage, the figures quoted represent fairly well the incidence at various levels, but by the time a diagnosis has been made the post cricoid cancers have often invaded the oesophagus deeply. The junction of the cervical and thoracic portions of the oesophagus is a site which is rarely attacked. All writers are agreed that cancer of the oesophagus generally is commoner in men, and this applies to the upper third even if the incidence of post-cricoid carcinoma in women is taken into account.

No more is known of the causation here than in other parts of the body, but the possibility of epithelioma arising in scar tissue has never been fully elucidated. Of the internal organs the oesophagus is particularly liable to be subjected to rough usage, though cicatrical structures generally form at a lower level. The tumours are almost invariably epitheliomas, the 20 per cent of adeno-carcinomas which occur in the oesophagus being all situated in its lower portion.

In the cervical oesophagus dysphagia is not only the cardinal symptom but the only early symptom in nearly every case. The substernal oppression and other related symptoms which are described relate to the lower portions of the oesophagus. In women this dysphagia often has lasted many years, so that it must have sometimes antedated the origin by a long period, and in such cases anaemia, smooth tongue and fissures at the corners of the mouth often accompany dysphagia. In women this long period of dysphagia is so constant in the history that it may almost be expected. Mackenzie has given an account of a woman aged 45 who consulted him for dysphagia in I863. He treated her with bougies and sedative drugs until I874 when a tumour was seen with a mirror in the deep pharynx and the patient died at the end of that year from an extensive cancer of the gullet. There are, however, a few cases in which dysphagia as an early symptom is absent or ignored, and the first manifestation of the disease is a goitre for which the patient seeks advice. Unless the morbid anatomy of cancer in this region is appreciated an erroneous diagnosis may easily be made and the neck explored with insufficient preparation. Not only does epithelioma in this situation come to surround the oesophageal tube and extend both upwards and downwards in the wall, but it is also likely to break outwards into the angle formed on either side by the margins of the trachea and the oesophagus. In this groove lies the recurrent laryngeal nerve covered by the posterior margin of the lateral lobe of the thyroid gland. If at an early stage the tumour breaks through into the thyroid gland at this spot, as it inevitably does at some period, a unilateral enlargement of the thyroid gland may be the only indication; but paralysis of the vocal cord on the same side should raise a suspicion of the true nature of the disease, which is easily revealed by a simple endoscopic examination. Hoarseness may be an initial symptom of cancer of the oesophagus, but if so the recurrent laryngeal nerve is then as likely to be caught in the thorax by a cancerous mediastinal gland as by a direct extension in the neck.

In the more advanced stages of the disease increasing dysphagia causes cough from overflow of mucus and saliva from the pharynx into the larynx. If both recurrent laryngeal nerves become entangled in growth or the invasion extends into the cricoarytenoideus posticus muscles, not only hoarseness but a double abductor paralysis may supervene rather rapidly with consequent dyspnoea which can only be relieved by tracheotomy. By this time dysphagia has become severe with consequent wasting, and this demands gastrostomy. Although the tumour begins as a flat plaque and often remains so on the cricoid plate, lower down it surrounds the 
CARCINOMA OF THE OESOPHAGUS-R. C. BROCK

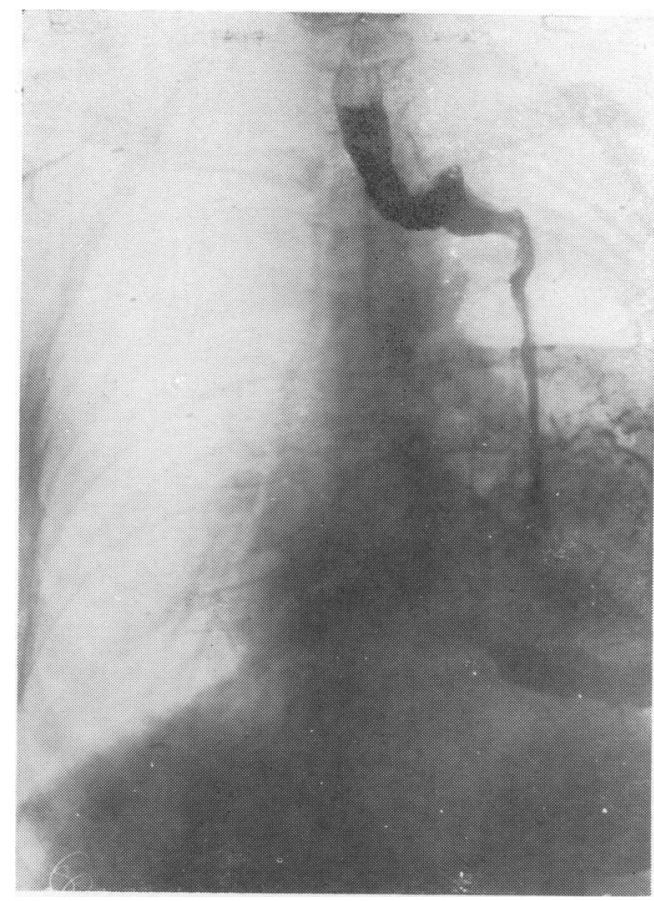

CARCINOMA OF THE UPPER THIRD-LIONEL COLLEDGE
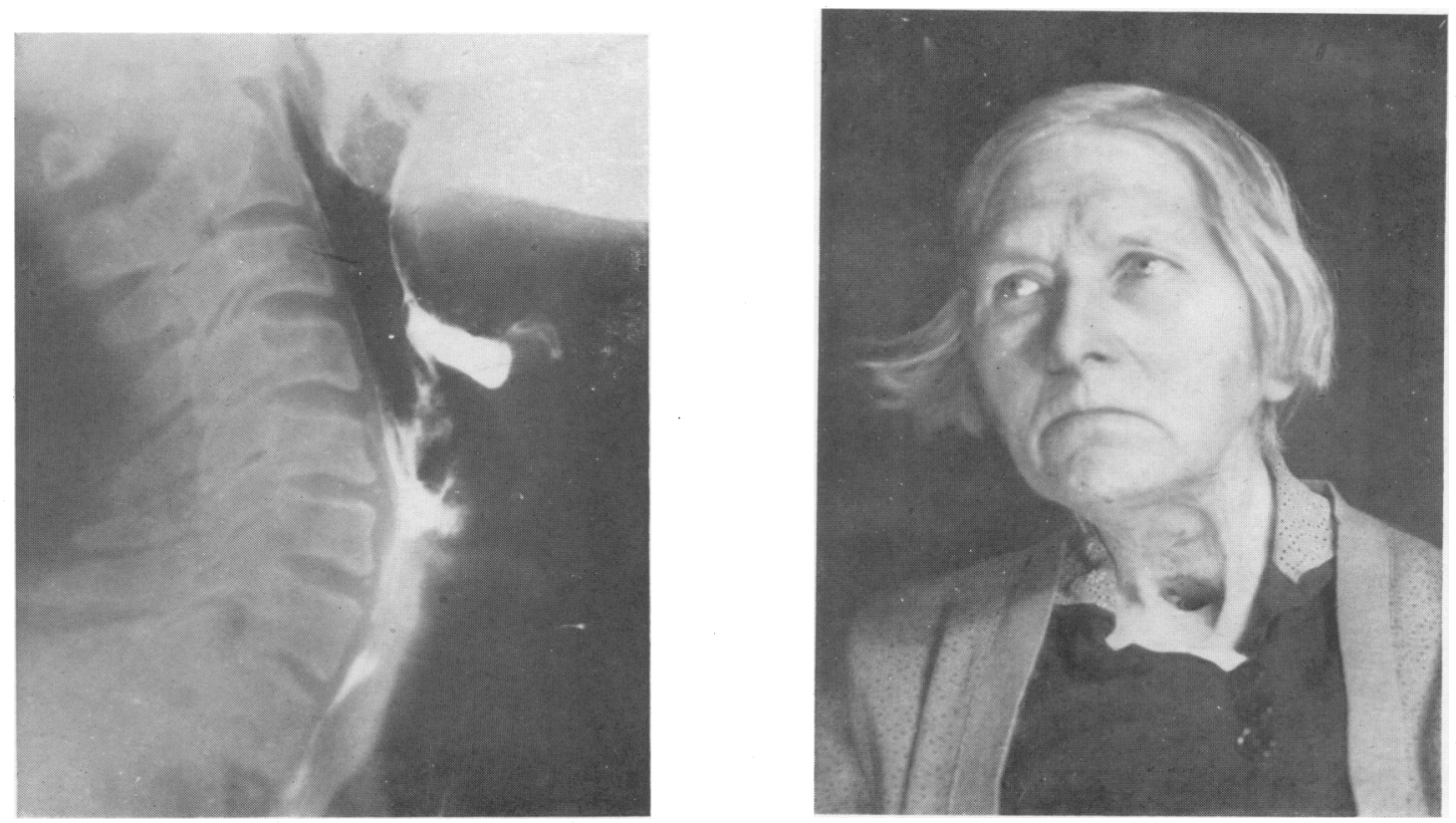
oesophageal lumen, and it is surprising sometimes to find this reduced to a stricture no more than a few millimetres in diameter and perhaps four or even five inches in length. Yet it is still possible to swallow liquids.

Should both tracheotomy and gastrostomy be indicated, the question constantly recurs whether this combination of palliative operations is worth while or even justifiable. They are both designed, however, rather to relieve symptoms of a peculiarly distressing and demoralising character rather than primarily to prolong life. Viewed from this angle these operations are worth while and should not be withheld, even if life is only prolonged for a matter of days, though palliative operations are from their nature disappointing.

It is natural when the field of surgical enterprise was extended widely by the introduction of Listerian principles attacks were soon made upon this terrible disease which is situated anatomically in a relatively accessible position. According to Morell Mackenzie the first attempt which met with any measure of success was made by Czerny. The patient was a woman aged 5I who had suffered from dysphagia for several months. Through a long incision on the left side of the neck the gullet containing the tumour was exposed and the upper six centimetres resected. The orifice of the lower part of the divided oesophagus was stitched to the skin and the patient was fed through a catheter left in the gullet. The patient remained in good health for several months feeding herself by means of a hollow sound passed as required. The lower end of the pharynx became shut off by scar tissue. The patient died more than a year later from a local recurrence. This was a favourable case for such an attempt, as there were no enlarged glands and the epithelioma was enclosed within the walls of the gullet.

In I899 De Quervain, in a paper on resection of the cervical portion of the oesophagus for carcinoma, described a case of his own and thirteen others, including the case of Czerny mentioned. 'Five patients died of the immediate effects of the operation, and one of Billroth's seven weeks later. Three died of purulent mediastinitis, those of Langenbeck and Bergmann immediately, and Billroth's from a split in the oesophagus.made by the feeding tube. Other patients died of secondary haemorrhage and heart failure, but another case of Czerny in r895, a woman aged 35, was more successful. One of Mikulicz survived II months, and one of Garre one year, but in none of the fourteen cases was a radical cure of the cancer obtained. De Quervain drew attention to the advanced condition of the disease when most of the patients are first seen, as is still the case, and suggested that this might make it necessary to resect the oesophagus at the level of the aortic arch. It is clear that these pioneer efforts were mostly made upon cases which would now be recognised as too advanced to offer any real hope of success and no effort was made to restore the continuity of the oesophagus. The patient had to depend either upon a feeding tube in the lower oesophagus or upon a gastrostomy, and in some of them life was maintained later by tracheotomy on account of bilateral fixation of the vocal cords in adduction.

To make the operation conform to modern surgical standards it must be confined to early cases and a means of uniting the pharynx with the oesophagus provided, so that the oesophageal lumen and normal swallowing is restored. Gluck, who refers to the work of v. Haeker, has related the story of those efforts which showed that attempts at direct suture have always failed, and gastrostomy was often necessary. In his Hunterian Lectures in I9I3 Trotter showed how this plastic repair of the oesophagus might be accomplished, by turning a horizontal flap of skin into the defect behind the larynx to form a bridge whose upper and lower edges are attached to the pharynx and oesophagus respectively. This provides a covering for all the raw surfaces and is thereby a major factor in controlling infection from the pharynx. When healing is complete the open gutter of skin can be converted by a further plastic operation into a closed tube and normal swallowing re-established.

The X-ray shows an early epithelioma situated just behind the upper end of the trachea in a man aged 68. Such a case is technically quite suitable for such an operation, but the patient died a year later from pulmonary metastases, and it must be admitted that even when this operation has been accomplished there is a liability to recurrence either in the lymphatic glands of the neck or locally, or even by metastases. Lane had performed this operation in I9og but a recurrence appeared in a few months.

In another case of my own, a woman aged 46 at the time of operation has lived for more than eight years with normal voice and swallowing but has recently developed a local recurrence. Another woman aged 49 in I 935 has remained free from recurrence 9 years although a nodule of growth was present in the thyroid gland. Unfortunately this case was complicated by post-operative gangrene of the skin. This gangrene did not affect the implanted skin but pre- 
vented the plastic closure of the oesophagus. However, the patient manages to swallow even liquids in a normal fashion in spite of the defect in the side of the neck.

Surgeon-Rear-Admiral G. Gordon Taylor tells me that a woman upon whom he operated in I932 remains well without recurrence, so that more than I2 years have elapsed, and Pilcher has reported that a patient upon whom Trotter operated was found to be free from recurrence at a necropsy ten years later.

It has been said that a fistula always forms, but this is not so if the rules of plastic surgery are faithfully observed. Skin flaps are turned in at the sides of the defect to provide an epithelial lining, and a pedicled flap obtained from the neighbourhood of the lower jaw is applied to the raw surface to form an outer layer of skin. These flaps, however, must all be of generous dimensions and stitched in position without tension. It is true that there is some wound infection from the pharyngeal secretion, but this soon passes and can be controlled by the applicacation of thin layers of proflavine and sulphathiazole to the raw surfaces.

This operation can only be profitably directed to quite early cases. If there be more than quite slight dysphagia, or if there be fixation of either vocal cord, indicating invasion of the larynx, or if the upper edge of the growth can be seen with a mirror behind the larynx, it will be found that it is impossible to peel the oesophagus off the back of the larynx without damaging the posticus muscles. If the dysphagia is severe it may be found also that the growth extends downwards as a circular stricture almost to the thoracic aperture.

Provided that the length of the stricture is not too great and that the growth has not broken through into the thyroid gland the operation, which Gluck recommended for all cases, of a complete resection of the larynx with a segment of pharynx and upper oesophagus is available.

In this operation two skin flaps are turned back on either side of the median line to expose the larynx and are used to bridge the gap between oesophagus and pharynx, the end of the trachea being fixed between them at the lower end and the oesophagus above it with a bridge of skin between the two apertures. When healing is complete the front of the pharynx and oesophagus is reconstructed by a plastic operation. This entails total loss of the larynx, but the patient finally is in the same state as after simple laryngectomy. This operation is particularly suitable for tumours of the fossa pyriformis. These tumours infiltrate the cartilaginous framework of the larynx at an early stage and radiation is therefore useless for them. Although the outlook is not good, this laborious operation gives a radical cure for many years in a proportion of cases and is therefore worth attempting in suitable cases. It can be adapted, as Gluck advised, to the tumours in question situated a little lower in the alimentary canal, and can give freedom from recurrence for many years. A man aged 65 underwent this operation for a circular epithelioma an inch in diameter at the upper end of the oesophagus with a mass of glands on the left side of the neck. The plastic reconstruction was undertaken three months later. $\mathrm{He}$ remains well with a perfectly healed pharynx for more than six years and converses easily with an artificial larynx.

The woman shown in the photograph, however, was the subject of a recurrence in the neck after three years.

Arthur Evans has recorded the case of a woman, aged 40, upon whom he performed an extensive operation of this type in rgog. She was well 23 years later but made use of a rubber oesophagus which connected the pharynx to a gastrostomy opening.

Too many cases, however, present themselves at a stage when neither of these operations can be undertaken with any prospect of success, and neither should be begun without a clear plan of the procedure required. Otherwise it may be necessary to abandon the operation, and if so the patient must be left with an oesophageal fistula through which feeding by liquids can be maintained. The best that can be said for this is that it forms an alternative to an otherwise inevitable gastrostomy. In such cases the only possible direct treatment is by radiation. Dr. Lederman has recently reported the results of treatment by radium beam in ${ }_{5} 5$ cases, in which it was ascertained that the tumour did not extend lower than the first dorsal vertebra. In tumours more deeply situated high voltage X-ray treatment must be substituted. Three have been kept free of symptoms for one year: one has developed metastases, four died of intercurrent disease within four years, one from distant metastases in less than two years, and six died of the primary disease in less than one year. Five patients died without evidence of disease in the treated area. This shows that radiotherapy can exert a valuable palliative effect and prolong life in comfort, but provides no evidence of any long period of freedom from recurrence nor of any radical cure. Miss Wood, however, informs me that of the 24 cases (treated by radium 
therapy) upon which she reported to the Medical Research Council in I938, two have remained well and free from symptoms for eight years, and another died from intercurrent disease without recurrence after remaining well for three years. None of Miss Wood's cases, however, were operable, so that it seems that treatment by irradiation has nearly always more to offer to the patient than excision. Operation is clearly justifiable in early carefully selected cases, but these are very few and are likely to remain so, and both from the point of view of palliation and possibility of radical cure irradiation is far more frequently the method of choice.

Although little mention has been made of extension to lymphatic glands both in neck and mediastinum, this is an important issue which always has to be taken into consideration in planning either surgical or radiological treatment.

GUISEZ, J. Semon Lecture, Journal of Laryngology, $1925,40,2$ I $_{3}$.

GLUCK, TH., and SORRENSEN, J., Handbuch der Speziellen Chirurgies Katz. Preysing, Blumenfeld, VV, 63 Wurzburg, Curtkabitzch, I9r4. ROLLESTON, H., System of Medicines (Allbutt and Rolleston), Vol. III, 343.

MACKENZIE, MÓRELL, Manual of Diseases of the Throat and Nose, Vol. II, p. 78, London: Churchill, 1884 .

DE QUERVAIN, F., Arch.f. Klin. Chir., r899, 858

TROTTER, W., Lancet, I913, I, xI52.

EVANS, A. Brit. Jour. of Surgery, 1933, 20, 388.

GORDON TAYLOR, G., Personal Communications.

PILCHER, R. Lancet., I937, I, 73.

LEDERMẢ, M., Proc. Roy. Soc. Med., 1944, 37, 335.

LANE, W. A. B.M.J., rgri, r, r6.

WOOD, CONSTANCE, Personal Communications and Report on Radium Beam Therapy Research, 1934-I938, p. 65, London: H.M. Stationery Office, 1938 .

\section{BOOK REVIEWS}

\section{NATURAL DEVELOPMENT OF THE CHILD}

By A. H. Rowley. 2nd Edition. E. \& S. Livingstone, Edinburgh. 1943. Price 8s. 6d.

This is an excellent book for teachers, the intelligent parent, and those working for the general welfare of children. It sets out in a clear style the normal reactions of a child at all ages to its environment and developing emotions. The lay-out of the book makes it easy to consult on any specific age period, and it should be a useful reference book. The photographs, with which it is illustrated, are charming.

\section{ORTHOPADIC SURGERY}

By Walter Mercer. 3rd edition. Edward Arnold \& Co., London. I944. Price 45 s.

This book, in a comparatively small space, contains an immense amount of information, but the necessary concentration makes it rather dull reading. At times the author's arguments are hard to follow; for example, he states that in the diagnosis of a protusion of an intervertebral disc "lumbar puncture is of value," but the only evidence of the value produced is that "raising of the total protein has been considered to be of diagnostic value, but the figures given by authorities vary so widely that its importance cannot be stressed," so one wonders wherein the value lies.

In the operative procedures more detail is given than is needed for a reader who desires to understand the principle of the operation, but not enough to enable a young surgeon to carry out the operation with confidence. One feels a sense of disappointment in this book, it seems to fall between being too big and yet not big enough.

\section{ILLUSTRATIONS OF REGIONAL ANATOMY}

By E. B. Jamieson. 5th Edition in seven sections (also in bound volume). E. \& S. Livingstone, Edinburgh. 1944. Price 75s. the complete set.

This wonderful collection of diagrams is unique, and surpasses anything I have seen in the anatomical atlases issued in other countries. It is true that the illustrations are diagrams rather than exact pictures, but this for the average student will increase their usefulness.

The fact that a work of seven parts, containing over 300 coloured plates, has reached its fifth edition so quickly, is sufficient proof of its popularity, as well as of the energy of its author and the enterprise of the publishers.

Illustrations which were not coloured or only partly coloured in previous editions have now received their full dress of colour; otherwise the only alteration is a minor re-arrangement by transferring one diagram from one part to another, and the addition of a very useful diagram in colour of the Anal and Urogenital Triangles in the Female.

Not only will this work be of the greatest help and use to students, but it will prove a very handy book of reference to those who practise surgery.

\section{VADE MECUM OF MEDICAL TREATMENT}

By W. Gordon Sears. 4th Edition. Edward Arnold \& Co., London. I943. Price Ios. 6d. net. - This handbook is a reliable guide to the various treatments which can be recommended for the commoner medical ailments, including eye and ear conditions. It has been well brought up to date; and is enriched with numerous prescriptions, thus increasing its usefulness to senior students and junior practitioners. There are also diet tables for diabetes and obesity. The arrangement is alphabetical, and there is an index. 